\title{
Retrospective Observational Assessment of Statin Adherence Among Subjects Patronizing Different Types of Community Pharmacies in Canada
}

\author{
Charity D. Evans, BSP; Dean T. Eurich, PhD; Darcy A. Lamb, MSc; \\ Jeffrey G. Taylor, PhD; Derek J. Jorgenson, PharmD; William M. Semchuk, PharmD; \\ Kerry D. Mansell, PharmD; and David F. Blackburn, PharmD
}

\begin{abstract}
BACKGROUND: Community pharmacies vary widely in terms of ownership structures, location, and dispensing policies. It is unknown if an association exists between the type of community pharmacy and the degree of medication adherence exhibited by patrons-patients.
\end{abstract}

OBJECTIVE: To describe adherence to statin therapy among subjects patronizing different types of community pharmacy categories (department-mass merchandise, chain-franchise, and independent-banner) in Saskatchewan, Canada, between 2000 and 2005.

METHODS: Study data were obtained from the Saskatchewan Drug Plan and Extended Benefits database, which is maintained by the government of Saskatchewan, Canada. The study included all subjects who (a) filled a statin prescription within selected community pharmacies between January 1, 2000, and December 31, 2005; (b) had no record of statin prescriptions during the year prior to the first statin prescription, according to the records of the Saskatchewan Drug Plan and Extended Benefits; and (c) demonstrated active utilization in the drug plan database for at least 1 year after the first statin prescription. The proxy criterion for activity was any dispensing record for statin or nonstatin medications at least 1 year following the index claim. Statin adherence level was estimated as tablets per day, defined as the total number of tablets dispensed divided by the total number of days of observation. Each subject's observation period began on the index date and ended on the earlier of (a) 30 days after the last recorded fill for any type of prescription medication (statin or nonstatin), or (b) December 31, 2005. The primary end point was the proportion of subjects within each pharmacy category who maintained an adherence level of $80 \%$ or greater during their individual observation period. Additional adherence calculations were performed for each of 3 time periods, beginning on the index date and ending on days 365,729 , and 1,094 (i.e., 1, 2, and 3 years). Patients were included in the analysis for each time period if they met a proxy criterion for availability for observation, defined as the dispensing of any drug at least 1 day after the end date of each period. Pearson chisquare tests were used to assess the significance of differences in baseline characteristics and adherence proportions, comparing pharmacy categories. Logistic regression analysis estimated the odds of an adherence level of at least $80 \%$ during the individual observation period, adjusting for pharmacy category, sex, age 65 years or older, known low-income drug coverage, number of distinct drug classes filled concurrently during the first year of observation, loyalty to index pharmacy, and length of observation. Using similar methods, we also estimated "pharmacy loyalty" by calculating the proportion of subjects who refilled $75 \%$ or more of their statin prescriptions at the pharmacy that dispensed their first statin prescription.

RESULTS: From an initial sample of 12,818 subjects who had at least 1 pharmacy claim for a statin in the period from January 1,2000 , through December 31, 2005, 8,699 subjects met the inclusion criteria. Subjects were observed for a mean (SD, range) of $3.7(1.7,1.0-7.0)$ years after the index statin prescription. During the first year following the index claim, statin adherence rates were at least $80 \%$ for 1,799 of $3,761(47.8 \%)$ patrons of department-mass merchandise, 1,778 of $3,235(55.0 \%)$ patrons of chain-franchise, and 921 of 1,703 (54.1\%) patrons of independent-banner stores $(P<0.001)$. Measured from the index date through day $1,094,869$ of 2,292 (37.9\%), 874 of $1,887(46.3 \%)$, and 457 of 975 (46.9\%) subjects in the department-mass merchandise, chain-franchise, and independentbanner categories, respectively, had a statin adherence level of at least $80 \%(P<0.001)$. In logistic regression analysis, pharmacy category type was significantly associated with statin adherence; subjects in the chainfranchise and independent-banner categories were more likely to be adherent to their statin medications during their observation periods than were those in the department-mass merchandise category (adjusted odds ratio $[0 \mathrm{R}]=1.36,95 \% \mathrm{Cl}=1.23-1.50, P<0.001$ and $\mathrm{OR}=1.39,95 \% \mathrm{Cl}=1.24-1.57$, $P<0.001$, respectively). From the index date through day $1,094,1,752$ of $2,292(76.4 \%), 1,475$ of $1,887(78.2 \%)$, and 795 of $975(81.5 \%)$ subjects remained pharmacy-loyal in the department-mass merchandise, chainfranchise, and independent-banner categories, respectively $(P=0.006)$. Controlling for several potential confounders using logistic regression, independent-banner pharmacy patrons were more likely to remain pharmacy-loyal during their observation periods than were those patronizing department-mass merchandise (adjusted $\mathrm{OR}=1.34,95 \% \mathrm{Cl}=1.16-1.54$, $P<0.001$ ) or chain-franchise stores (adjusted $\mathrm{OR}=1.22,95 \% \mathrm{Cl}=1.06-1.42$, $P=0.009$ ).

CONCLUSION: One year after their first statin fill, subjects demonstrated low rates of adherence, ranging from $48 \%$ to $55 \%$, regardless of the type of pharmacy they patronized. Although the differences by type of pharmacy reached statistical significance, their clinical importance is not evident, reinforcing the fact that the problem of nonadherence appears to exist among all types of community pharmacies, regardless of their categorization.

J Manag Care Pharm. 2009;15(6):476-84

Copyright $\odot$ 2009, Academy of Managed Care Pharmacy. All rights reserved.

\section{What is already known about this subject}

- Statin medications should be taken on a long-term basis to obtain the benefits of reductions in cardiovascular morbidity and mortality. However, adherence to statin medications is known to be poor.

- In a study of pharmacy characteristics associated with statin adherence, Pedan et al. (2007) found higher adherence in pharmacies with more statin patients, increasing at a rate of $28.4 \%$ for each additional 100 patients per patronized pharmacy.

- In a study comparing adherence rates for patients patronizing different pharmacy types, Kalsekar et al. (2007) found slightly higher adherence in subjects receiving oral hypoglycemic agents at independent pharmacies compared with chain pharmacies. However, the adherence measure was not applied to subjects who discontinued therapy, and only 2 types of pharmacies were compared. 


\section{Retrospective Observational Assessment of Statin Adherence Among Subjects Patronizing Different Types of Community Pharmacies in Canada}

\section{What this study adds}

- To our knowledge, this is the first large-scale comparison of statin adherence in patients patronizing different types of community pharmacies. However, this study of administrative claims data was conducted (a) without eligibility data, and the eligibility proxy (presence of any pharmacy claim) resulted in removing eligible but nonpersistent statin users from the sample if a statin was their only medication; and (b) without days supply, which required the use of tablets per day of observation as a proxy for statin adherence.

- During the first 3 years of statin therapy, less than $50 \%$ of subjects demonstrated adherence of at least $80 \%$ regardless of the type of pharmacy they patronized. The lowest proportion of adherent patients (37.9\%) was observed in department-mass merchandise stores, compared with $46.3 \%$ patronizing chain-franchise stores and $46.9 \%$ patronizing independent-banner stores.

- During the first year of statin therapy, more than $85 \%$ of subjects filled at least $75 \%$ of their statin prescriptions at the pharmacy where the original prescription was filled. However, over a 3-year period, independent-banner pharmacy patrons were more likely to maintain this pharmacy loyalty (81.5\%) compared with those patronizing department-mass merchandise (76.4\%) or chainfranchise stores (78.2\%)

$\mathrm{I}$ Canada, most prescription medications are dispensed by licensed pharmacists through community pharmacies. Because of their frequent contact with patients, it has been suggested that community pharmacists are in an ideal position to identify and improve medication nonadherence. ${ }^{1}$ However, community pharmacies can vary widely in terms of ownership structures, location, and dispensing policies. It is possible that these organizational policies could influence medication-taking behavior among certain patients.

Little is known about the impact that different types of community pharmacies have on medication adherence. It has been suggested that independently owned pharmacies provide better service, ${ }^{2,3}$ but these observations have not been confirmed by objective data. A recent study by Kalsekar et al. found slightly higher adherence in subjects receiving oral hypoglycemic agents at independent pharmacies compared with chain pharmacies. ${ }^{2}$ However, the adherence measure was not applied to subjects that discontinued their therapy, and only 2 types of pharmacies were compared. A second study by White et al. determined that subjects using a mail service pharmacy exhibited a higher degree of adherence to statins than those who used community pharmacies. ${ }^{4}$ However, the comparison was limited to a single mail order pharmacy where financial incentives were provided to clients for using this service. Also, no distinction was made between the types of community pharmacies used for comparison. ${ }^{4}$

Medication nonadherence is a global problem and is a predictor of negative patient outcomes. ${ }^{5-7}$ Although many studies have examined predictors of medication adherence, few have examined whether distinct categories of community pharmacies influence medication adherence. Because limited information is available, we designed a preliminary and exploratory study to evaluate whether general trends in medication adherence can be identified among subjects patronizing different categories of community pharmacies between 2000 and 2005.

\section{Methods}

\section{Data Source}

All study data were obtained from the Saskatchewan Drug Plan and Extended Benefits database, which is maintained by the government of Saskatchewan, Canada. All Saskatchewan pharmacies are equipped with electronic point-of-service terminals that submit to the drug plan fields such as patient identifier, date of dispensing, product name, and quantity. A days supply variable was not captured during the period of study. The drug plan database also contains drug coverage information for known low-income (e.g., social assistance) subjects. Prescription fills for medications listed in the comprehensive provincial formulary are captured for approximately $90 \%$ of the province's population of nearly 1 million. Residents ineligible for coverage under the drug plan include approximately $9 \%$ of the population (primarily Registered Indians) whose prescription costs are paid by another government agency.

\section{Subject Selection}

We created a retrospective cohort study using a new-user design ${ }^{8}$ of all drug plan beneficiaries filling a new statin prescription in selected community pharmacies between January 1, 2000, and December 31, 2005. A new statin prescription was defined as having no fills for a statin drug in the previous year as recorded by the Saskatchewan Drug Plan and Extended Benefits. ${ }^{9}$ In the year prior to the index statin prescription, $88.4 \%$ of subjects $(7,693$ of 8,699$)$ filled at least 1 prescription for a medication other than a statin. The mean (SD) duration between the first recorded prescription in the previous year and the date of the index statin prescription was 269 (128) days. Because we used prescription fills as a proxy for beneficiary status, we cannot be entirely sure that all patients were truly new users. However, the proportions of subjects without prior fills were distributed evenly among the pharmacy categories used in the present study (ranging from $10.9 \%$ to $12.0 \%, P=0.487$ ). Sensitivity analyses excluding these patients from the analysis produced similar results (data available on request). The statin class of medications was selected for analysis because adherence to these medications is known to be poor, ${ }^{6,9-12}$ and our research group has experience with statin adherence analyses using Saskatchewan health data., ${ }^{71}$

\section{Community Pharmacy Selection}

Community pharmacy companies that provide service to the urban centers in Saskatchewan were subjectively grouped into 


\section{Retrospective Observational Assessment of Statin Adherence Among Subjects}

Patronizing Different Types of Community Pharmacies in Canada

\section{TABLE 1 Categorization of Canadian Community Pharmacies}

\begin{tabular}{l|c|c|c|c|c}
\hline & $\begin{array}{c}\text { Department-Mass } \\
\text { Merchandise }\end{array}$ & Chain & Franchise & Banner \\
\hline Size of dispensary (square feet) & 683 & 786 & 1,012 & 877 \\
\hline Size of frontshop (square feet) & 7,496 & 3,771 & 6,279 & 2,484 \\
\hline Dispensary hours open (weekly) & 69 & 69 & 85 & 65 \\
\hline Average annual prescription volume & 33,752 & 71,617 & 84,292 & 62,008 \\
\hline Annual sales (\$ millions) & 2.58 & 4.42 & 5.91 & 55 \\
\hline Adapted from: The Pharmacy Group. Trends and Insights 2007.13 & & & 2.62 \\
\hline
\end{tabular}

3 categories on the basis of typical store type: department-mass merchandise, chain-franchise, and independent-banner ${ }^{13}$ (Table 1). Department-mass stores are large chains that sell a wide variety of merchandise. Typically, a pharmacy department is included in these stores as just 1 of many departments that may also include clothing, sporting goods, groceries, and housewares. In Saskatchewan, department-mass merchandise stores are often referred to as "big-box" stores because of their physical appearance. Chain-franchise stores are also large chains but are devoted primarily to the practice of pharmacy. Although additional types of merchandise, especially health products, vitamins, and cosmetics, are sold in these stores, the primary and central activity is the dispensing of prescriptions. Finally, Saskatchewan still has a number of active pharmacies that are owned and operated by a single individual (owner-operator). They are generally small and located in residential communities, functioning like the "corner store." For buying purposes, these independent pharmacies sometimes cooperate under a single "banner" in order to obtain better discounts on their wholesale products. However, even if they share the same banner, they continue to operate independently.

A list of pharmacies servicing Saskatchewan was categorized as above and provided to Saskatchewan Drug Plan and Extended Benefits personnel who independently selected a representative sample of community pharmacies to be included in our study. In order to ensure that researchers were blinded, drug plan personnel excluded stores that newly opened or closed during the observation period because it might have been possible for the investigators to identify specific pharmacies by comparing relevant dates from the data provided.

Ultimately, 6 department-mass merchandise stores representing 2 companies (chains), 12 separate chain-franchise stores representing 3 companies (chains), and 16 independent-banner stores were selected. Although this sampling procedure was not random, it was performed by government employees who were not involved in the study. All except 1 of the selected pharmacies were located in the 2 largest centers in Saskatchewan and represented approximately 35\% of all pharmacies in these 2 cities $(n=93)$. These pharmacies provided over 3,000 new statin users from each of the department-mass category and the chain-franchise category. However, because the number of subjects receiving statin prescriptions from the independent-banner category was much lower, selection of 16 stores resulted in approximately 1,700 eligible subjects to represent this cohort. Subject- and store-specific information was de-identified by Saskatchewan Drug Plan personnel before being provided to the researchers. All statin fills in the selected pharmacies were distinguished by a unique pharmacy identifier. Statin and other prescriptions filled in other (nonstudy) Saskatchewan pharmacies were captured, but the pharmacy type could not be distinguished.

\section{Outcome Measures and Observation Period}

Subjects were divided into 3 cohorts based on the type of pharmacy that dispensed the first (i.e., index) statin prescription: department-mass merchandise, chain-franchise, and independent-banner. Individual subject observation periods began on the date of the index prescription and were censored 30 days after the last recorded fill for any type of prescription medication or at the end of the observation period (i.e., December 31, 2005). Only those subjects with an observation period of at least 1 year were included.

The primary end point was the proportion of patients within each category remaining adherent to statin medications. Subjects were classified as adherent if they exhibited at least $80 \%$ adherence (optimal adherence) over their observation period. The $80 \%$ threshold is easily defined and commonly used in similar studies measuring adherence. ${ }^{6,11,14}$ Subjects with an adherence of greater than $100 \%$ were included in the analysis. However, only $1 \%$ of the subjects exhibited an adherence of greater than $110 \%$, and the distribution was similar among pharmacy categories (data available upon request). Since subjects could switch pharmacies during the observation period, we calculated the proportion of subjects in each category who remained loyal to their original pharmacy as a secondary end point. Subjects were classified as pharmacy-loyal if $75 \%$ or more of their total statin prescriptions were dispensed from the pharmacy where the index prescription was filled. 


\section{Retrospective Observational Assessment of Statin Adherence Among Subjects \\ Patronizing Different Types of Community Pharmacies in Canada}

\section{TABLE 2 Baseline Characteristics of Subjects}

\begin{tabular}{|c|c|c|c|c|c|c|c|}
\hline \multirow[b]{2}{*}{ Characteristic } & \multicolumn{2}{|c|}{$\begin{array}{c}\text { Department-Mass } \\
\text { Merchandise } \\
\mathbf{n}=3,761\end{array}$} & \multicolumn{2}{|c|}{$\begin{array}{c}\text { Chain-Franchise } \\
\mathrm{n}=3,235\end{array}$} & \multicolumn{2}{|c|}{$\begin{array}{l}\text { Independent-Banner } \\
\qquad \mathrm{n}=1,703\end{array}$} & \multirow[t]{3}{*}{$P$ Value $^{\mathrm{a}}$} \\
\hline & & & & & & & \\
\hline Male (\%) & 2,065 & $(54.9)$ & 1,796 & $(55.5)$ & 944 & $(55.4)$ & \\
\hline Aged 65 years or older $(\%)$ & 1,483 & $(39.4)$ & 1,026 & $(31.7)$ & 694 & $(40.8)$ & $<0.001$ \\
\hline Known low-income drug coverage $(\%)^{\mathrm{b}}$ & 544 & $(14.5)$ & 501 & (15.5) & 298 & $(17.5)$ & 0.016 \\
\hline \multicolumn{8}{|c|}{ Number of medication classes in prior year (\%) } \\
\hline None & 248 & $(6.6)$ & 182 & $(5.6)$ & 105 & $(6.2)$ & 0.001 \\
\hline $1-2$ & 916 & $(24.4)$ & 743 & $(23.0)$ & 365 & $(21.4)$ & \\
\hline $3-4$ & 1,129 & $(30.0)$ & 915 & $(28.3)$ & 471 & $(27.7)$ & \\
\hline 5 or more & 1,468 & $(39.0)$ & 1,395 & $(43.1)$ & 762 & $(44.7)$ & \\
\hline \multicolumn{8}{|l|}{ Length of observation period (\%)d } \\
\hline $365-729$ days & 753 & $(20.0)$ & 660 & $(20.4)$ & 365 & $(21.4)$ & 0.043 \\
\hline 730-1,094 days & 716 & $(19.0)$ & 688 & $(21.3)$ & 363 & $(21.3)$ & \\
\hline 1,095 days or more & 2,292 & $(60.9)$ & 1,887 & $(58.3)$ & 975 & $(57.3)$ & \\
\hline \multicolumn{8}{|c|}{$\begin{array}{l}\text { aPearson chi-square (3-way comparison). } \\
\text { bIndicates that the patient was receiving some form of prescription benefit (e.g., shared copayments) from the Saskatchewan Drug Plan and Extended Benefits branch of the } \\
\text { Saskatchewan government. } \\
\text { 'Based on American Hospital Formulary System (AHFS) classification. } \\
\text { dObservation periods began on the date of the index prescription and were censored on the earlier of } 30 \text { days after the last recorded fill for any type of prescription medica- } \\
\text { tion or the end of the observation period (i.e., December 31, 2005). }\end{array}$} \\
\hline
\end{tabular}

\section{Data Analysis}

Adherence was estimated using the "tablets per day" calculation. ${ }^{15}$ The tablets per day measure is calculated by taking the total number of tablets dispensed divided by the total number of days of observation. For example, 80 tablets dispensed over a 100 -day observation period would be calculated as $80 \%$ adherence. Switching between statin medications was allowed. This method is considered reliable because statins are almost exclusively administered as a single daily dose..$^{15}$ In addition, it has been used previously to assess statin adherence using administrative data, ${ }^{15}$ and we have found it to be highly correlated to another measure of adherence, the fill frequency. ${ }^{7}$ Persistence was estimated as the length of time between the index prescription and date of discontinuation. ${ }^{15}$ The date of discontinuation was defined as the earlier of the last recorded statin fill date during the subject's individual observation period or the end of the study period (December 31, 2005).

Baseline characteristics of subjects and adherence rates among the 3 pharmacy categories were compared using Pearson chisquare tests. Multivariate logistic regression analyses were used to evaluate the association between pharmacy categories and subject adherence throughout the entire observation period, as well as to evaluate pharmacy loyalty. In the models, optimal adherence (less than $80 \%$ vs. at least $80 \%$ ) was the dichotomous dependent variable of interest. In addition to the pharmacy category attended, a number of patient-level covariates were also included: years of observation, known low-income drug coverage, number of distinct drug categories (by American Hospital Formulary Service
[AHFS] classification) filled concurrently during the first year of observation, sex, age 65 years or older, and loyalty to the index pharmacy. All first-order interactions were evaluated with none significant. In addition to calculating overall adherence, measured throughout the entire observation period for each subject, we also calculated adherence during 3 time periods beginning on the index date and ending, respectively, at 1 year (365 days), 2 years ( 729 days), and 3 years (1,094 days) after the start of statin therapy. In order to qualify for these adherence calculations, subjects were required to have an observation period that ended after the year of interest. In other words, subjects were required to have filled a prescription of any type (statin or nonstatin) in the year subsequent to the one being evaluated.

In a sensitivity analysis, we calculated adherence for statins using a different method, the fill frequency (dispensings per months of observation $)^{7}$ and re-analyzed the data as described above. This sensitivity analysis resulted in trends similar to our primary analysis (data not shown).

Analyses were carried out using SPSS version 16.0 for Windows (SPSS, Inc., Chicago, IL). The study protocol was granted a letter of exemption by the University of Saskatchewan Biomedical Research Ethics Board.

\section{Results}

Overall, 12,818 subjects filled at least 1 statin prescription at the selected pharmacies between 2000 and 2005. Subjects with statin fills recorded in the prior year $(n=3,709)$ and those with an observation period less than 1 year $(n=410)$ were excluded, leaving 8,699 new users of statin therapy eligible for analysis 


\section{Retrospective Observational Assessment of Statin Adherence Among Subjects \\ Patronizing Different Types of Community Pharmacies in Canada}

\section{TABLE 3 Number and Percent of Subjects Adherent to a Statin}

Overall and During 1-Year, 2-Year, and 3-Year Periods

\begin{tabular}{|c|c|c|c|c|}
\hline Pharmacy Category & Overall & Index Through Year $1^{\mathrm{b}}$ & Index Through Year $2^{\mathrm{b}}$ & Index Through Year $3^{b}$ \\
\hline Number of subjects & & 8,699 & 6,921 & 5,154 \\
\hline Department-mass merchandise ${ }^{c}$ & $1,414 \quad / \quad 3,761 \quad(37.6)$ & $1,799 / 3,761 \quad(47.8)$ & $1,203 / 3,008(40.0)$ & 869 / 2,292 (37.9) \\
\hline Chain-franchise ${ }^{c}$ & $1,456 / 3,235(45.0)$ & $1,778 / 3,235(55.0)$ & $1,255 / 2,575(48.7)$ & $874 / 1,887(46.3)$ \\
\hline Independent-bannerc & $784 / 1,703(46.0)$ & $921 / 1,703(54.1)$ & $663 / 1,338$ (49.6) & $457 / 975(46.9)$ \\
\hline
\end{tabular}

aAdherence was defined as tablets per day (number of tablets dispensed divided by the total number of days of observation) equal to at least $80 \%$ during each of the 3 observation periods. Overall adherence was measured throughout each subject's entire observation period. Each subject's observation period began on the date of the index prescription and was censored on the earlier of 30 days after the last recorded fill for any type of prescription medication or the end of the observation period (i.e., December 31, 2005). Results for the 1-, 2-, and 3-year time periods, respectively, were measured from the index date through 365, 729, and 1,094 days. Because we did not have eligibility data, the results for each time period include only subjects with at least 1 prescription claim for any medication filled after the end of the time period. ${ }^{b}$ Comparisons of proportion of subjects with adherence of at least $80 \%$ among all 3 pharmacy categories using Pearson chi-square tests were significant $(P<0.001)$ for all time periods measured.

${ }^{c}$ Cells indicate number adherent/total number (\%).

\section{FIGURE 1 Sample Selection Flowchart}

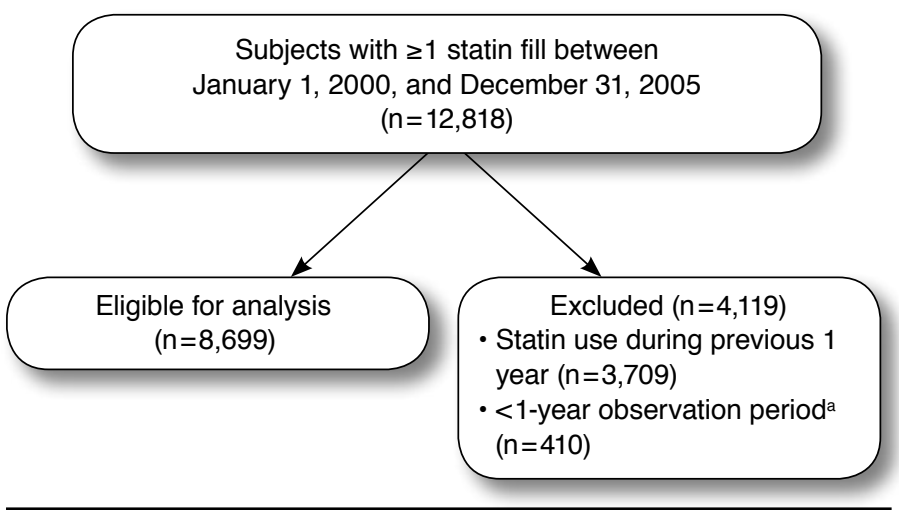

a Observation periods began on the date of the index prescription and were censored on the earlier of 30 days after the last recorded fill for any type of prescription medication or the end of the observation period (i.e., December 31, 2005).

(Figure 1). Few differences in baseline characteristics were observed among the 3 categories (Table 2). Subjects in the chainfranchise cohort were younger than those in the departmentmass or independent-banner categories, whereas subjects in the independent-banner category filled prescriptions for more classes of concurrent medications and had a slightly higher proportion of known low-income drug coverage compared with subjects in the other 2 categories. Mean length of observation for all subjects was 3.7 years (range 1.0-7.0 years), and the majority of subjects in each pharmacy category had an observation length of at least 3 years.

Measured throughout each subject's entire observation period, $37.6 \%(1,414$ of 3,761$)$ of patrons of department-mass merchandise stores, $45.0 \%$ (1,456 of 3,235) of patrons of chain-franchise stores, and $46.0 \%$ (784 of 1,703) of patrons of independentbanner stores had a statin adherence rate, measured as tablets per day, of at least $80 \%(P<0.001$; Table 3$)$. During the same time period, mean tablets per day of observation were $0.632,0.573$, and 0.632 in the department-mass merchandise, chain-franchise stores, and independent-banner categories, respectively $(P<0.001$ by 3-way Analysis of Variance; data not shown). Mean persistence (length of time between first and last statin fill) was 2.8 years in both the department-mass merchandise and chain-franchise categories and 2.9 years in the independent-banner category $(P=0.587$; data not shown $)$.

During the first year following the index statin prescription, 1,799 of 3,761 (47.8\%), 1,778 of 3,235 (55.0\%), and 921 of 1,703 (54.1\%) subjects in the department-mass merchandise, chainfranchise, and independent-banner categories, respectively, had an adherence level of $80 \%$ or more $(P<0.001$; Table 3$)$. Adherence among subjects in all 3 pharmacy categories continually declined over the 3 years. Of subjects with an observation period of at least 3 years $(n=5,154), 869$ of 2,292 (37.9\%) department-mass merchandise, 874 of 1,887 (46.3\%) chain-franchise, and 457 of 975 (46.9\%) independent-banner subjects remained adherent to statin therapy $(P<0.001)$.

In logistic regression analysis, pharmacy category type was significantly associated with overall statin adherence (Table 4). Subjects in the chain-franchise and independent-banner categories were more likely to be adherent to their statin medications during their observation periods than were those in the department-mass merchandise category (adjusted odds ratio $[O R]=1.36,95 \% C I=1.23-1.50, P<0.001$, and $O R=1.39,95 \%$ $\mathrm{CI}=1.24-1.57, P<0.001$, respectively). No significant difference was observed when comparing the chain-franchise with independent-banner categories (adjusted $\mathrm{OR}=0.98,95 \% \mathrm{CI}=0.87$ $1.10, P=0.717$; data not shown). Adherence of at least $80 \%$ was more likely for subjects aged 65 years or older than for younger subjects $(P<0.001)$ and for those receiving 1 or more concurrent prescription medications than for those receiving no concurrent medications $(P<0.01)$. Female sex and low-income drug coverage were associated with less optimal adherence $(P \leq 0.001)$.

Loyalty to the index pharmacy was high, and among subjects 


\section{Retrospective Observational Assessment of Statin Adherence Among Subjects \\ Patronizing Different Types of Community Pharmacies in Canada}

\section{TABLE 4 Predictors of Statin Adherence During Entire Observation Period ${ }^{a}$}

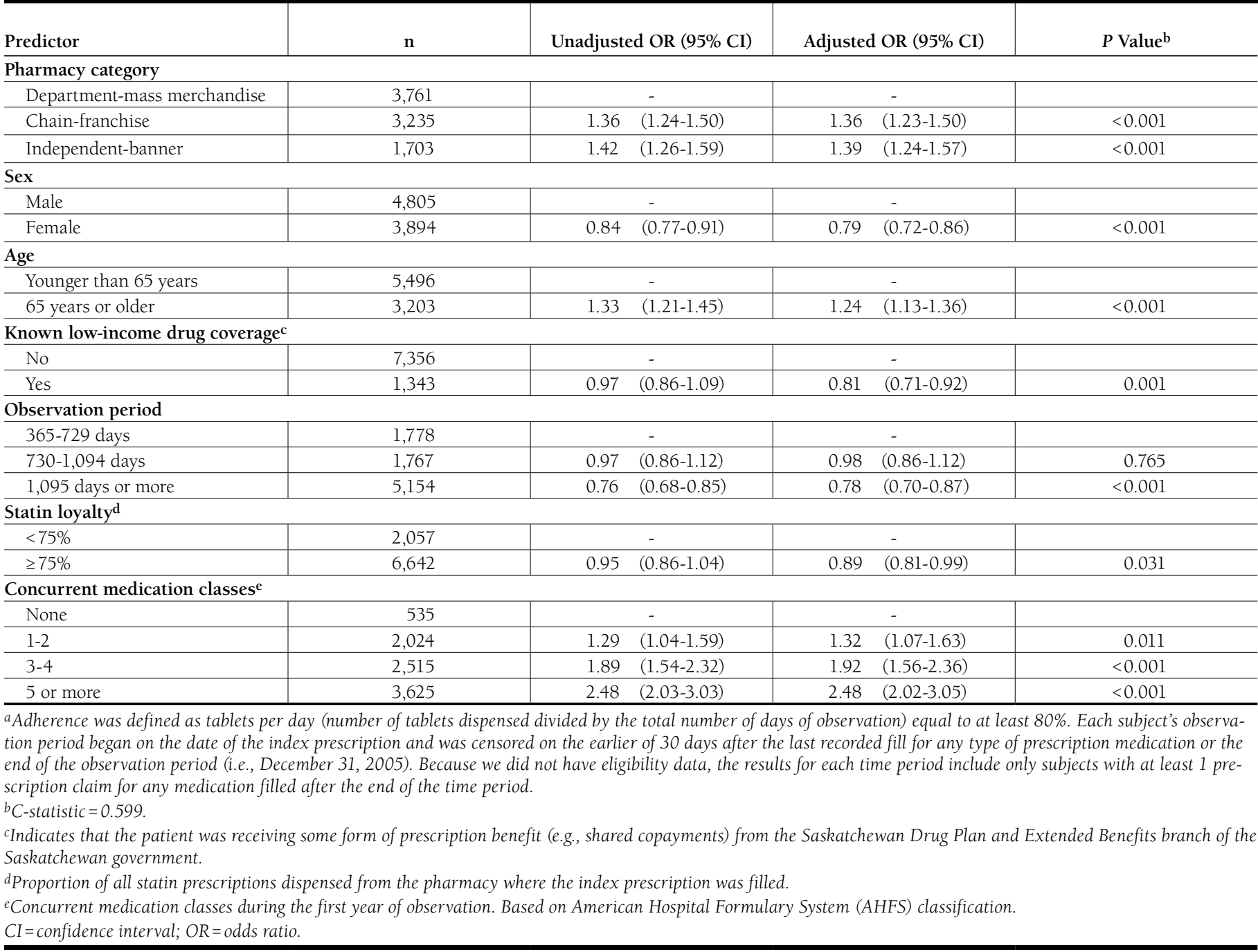

with 3 years of observation ( $n=5,154), 1,752$ of 2,292 (76.4\%) in the department-mass merchandise, 1,475 of 1,887 (78.2\%) in the chain-franchise, and 795 of 975 (81.5\%) in the independentbanner pharmacy categories filled more than $75 \%$ of their statin prescriptions at their index pharmacy $(P=0.006$; Table 5). Overall, subjects in the independent-banner pharmacy category were more likely to remain loyal to their index pharmacy than were those patronizing department-mass merchandise (adjusted $\mathrm{OR}=1.34,95 \% \mathrm{CI}=1.16-1.54, \mathrm{P}<0.001$; Table 6) or chain-franchise stores (adjusted $\mathrm{OR}=1.22,95 \% \mathrm{CI}=1.06-1.42, P=0.009$; data not shown). No significant difference in subject pharmacy loyalty was observed when comparing the chain-franchise with department-mass merchandise categories (adjusted $\mathrm{OR}=1.10$, 95\% CI $=0.99-1.23, P=0.084)$.

\section{Discussion}

In our study of community pharmacy categories, we found significant differences in adherence to statin therapies. Compared with patrons of department-mass merchandise stores, patrons of chain-franchise and independent-banner stores were more likely to remain adherent to statin medications, as measured by tablets per day of $80 \%$ or more, independent of age, sex, concurrent medication use, or known low-income drug coverage. No significant difference in statin adherence was observed between the chain-franchise and independent-banner stores. Mean tablets per day of observation for patrons of department-mass merchandise and independent-banner stores were approximately equal, and mean persistence was approximately 2.8 to 2.9 years regardless of pharmacy type.

Kalsekar et al. found that subjects receiving oral hypoglycemic 


\section{Retrospective Observational Assessment of Statin Adherence Among Subjects \\ Patronizing Different Types of Community Pharmacies in Canada}

\section{TABLE 5 Number and Percent of Subjects Exhibiting Pharmacy}

Loyalty During 1-Year, 2-Year, and 3-Year Periodsa

\begin{tabular}{l|c|c|c}
\hline Pharmacy Category & Year 1 & Year 2 & Year 3 \\
\hline Number of subjects & 8,699 & 6,921 & 5,154 \\
\hline Department-mass merchandise (\%) & $3,225 / 3,761(85.7)$ & $2,438 / 3,008(81.1)$ & $1,752 / 2,292(76.4)$ \\
\hline Chain-franchise (\%) & $2,777 / 3,235(85.8)$ & $2,104 / 2,575(81.7)$ & $1,475 / 1,887(78.2)$ \\
\hline Independent-banner (\%) & $1,511 / 1,703(88.7)$ & $1,136 / 1,338(84.9)$ & $795 / 975(81.5)$ \\
\hline$P$ value & $<0.001$ & 0.008 & 0.006 \\
\hline
\end{tabular}

aPharmacy loyalty was defined as at least 75\% of all statin prescriptions being dispensed from the pharmacy where the index prescription was filled. Results for the 1-, 2-, and 3-year time periods, respectively, were measured from the index date through 365, 729, and 1,094 days. Because we did not have eligibility data, the results for each time period include only subjects with at least 1 prescription claim for any medication filled after the end of the time period.

${ }^{b} \mathrm{P}$ value for 3-way comparison of pharmacy-loyal proportions.

\section{TABLE 6 Predictors of Pharmacy Loyalty}

Predictor n Unadjusted OR (95\% CI) Adjusted OR (95\% CI)

$P$ Value $^{\mathrm{b}}$

Pharmacy category

Department-mass merchandise

Chain-franchise

Independent-banner

3,761

\begin{tabular}{|l}
3,761 \\
3,235 \\
\hline 1,703
\end{tabular}

Sex

\begin{tabular}{|c|c|c|c|c|c|c|}
\hline Male & 4,805 & & - & & - & \\
\hline Female & 3,894 & 1.20 & $(1.08-1.32)$ & 1.22 & $(1.10-1.35)$ & $<0.001$ \\
\hline \multicolumn{7}{|l|}{ Age } \\
\hline Younger than 65 years & 5,496 & & - & & - & \\
\hline 65 years or older & 3,203 & 1.16 & (1.04-1.28) & 1.19 & $(1.06-1.33)$ & 0.002 \\
\hline
\end{tabular}

Known low-income drug coverage ${ }^{c}$

\begin{tabular}{|l|r}
\hline No & 7,356 \\
\hline Yes & 1,343
\end{tabular}

Yes

1,343

1.09

Observation period

\begin{tabular}{l} 
365-729 days \\
\hline 730-1,094 days \\
\hline 1,095 days or more
\end{tabular}

\begin{tabular}{|l}
1,778 \\
1,767 \\
5,154
\end{tabular}

\begin{tabular}{l}
1,778 \\
1,767 \\
5,154 \\
\hline
\end{tabular}

\begin{tabular}{|ll|}
\hline & - \\
0.83 & $(0.72-0.94)$
\end{tabular}

\begin{tabular}{|ll}
\hline & - \\
\hline & $0.74 \quad(0.64-0.85)$
\end{tabular}

$\mid<0.001$

Statin adherenced

\begin{tabular}{|c|c|c|c|c|c|c|}
\hline$<80 \%$ & 5,045 & & - & & - & \\
\hline$\geq 80 \%$ & 3,654 & 0.95 & $(0.86-1.05)$ & 0.89 & $(0.81-0.99)$ & 0.029 \\
\hline \multicolumn{7}{|c|}{ Concurrent medication classes $^{\mathrm{e}}$} \\
\hline None & 535 & & - & & - & \\
\hline $1-2$ & 2,024 & 1.32 & $(1.07-1.63)$ & 1.32 & $(1.06-1.63)$ & 0.012 \\
\hline $3-4$ & 2,515 & 1.45 & $(1.17-1.78)$ & 1.42 & $(1.15-1.76)$ & 0.001 \\
\hline 5 or more & 3,625 & 1.37 & (1.08-1.61) & 1.26 & $(1.02-1.56)$ & 0.029 \\
\hline
\end{tabular}

aPharmacy loyalty was defined as at least $75 \%$ of all statin prescriptions being dispensed from the pharmacy where the index prescription was filled.

${ }^{b}$ C-statistic $=0.764$.

'Indicates that the patient was receiving some form of prescription benefit (e.g., shared copayments) from the Saskatchewan Drug Plan and Extended Benefits branch of the Saskatchewan government.

${ }^{d}$ Adherence was defined as tablets per day (number of tablets dispensed divided by the total number of days of observation). Because we did not have eligibility data, the results for each time period include only subjects with at least 1 prescription claim for any medication filled after the end of the time period.

${ }^{e}$ Concurrent medications classes during the first year of observation. Based on American Hospital Formulary System (AHFS) classification.

$C I=$ confidence interval $; O R=$ odds ratio.

agents at an independent pharmacy had a 1.7\% higher adherence compared with those receiving their prescriptions at a chain pharmacy. ${ }^{2}$ However, the follow-up period was relatively short (1 year), and their analysis did not include department-mass merchandise pharmacies. ${ }^{2}$

The statin adherence rates observed in the present study after 


\section{Retrospective Observational Assessment of Statin Adherence Among Subjects Patronizing Different Types of Community Pharmacies in Canada}

3 years (37.9\%, 46.3\%, and 46.9\% for department-mass merchandise, chain-franchise, and independent-banner, respectively) are comparable to those found in previously published studies.9-12 Other recent reports have observed statin adherence rates even lower than those reported in the present study. ${ }^{16-18}$ Although nonadherence to statins has been widely cited, it is likely that adherence to other chronic cardiovascular medications is equally poor. ${ }^{10}$

Despite overall low adherence, pharmacy loyalty among our study subjects was high in all 3 pharmacy categories. Independent-banner pharmacies were associated with a greater loyalty over 3 years of observation than were chain-franchise or department-mass merchandise stores (81.5\%, 78.2\%, and $76.4 \%$, respectively), but the observed differences were small and are of questionable importance. This observation is important because it suggests that individuals commonly rely on a single pharmacy for their chronic medications.

A strength of our study is the real-world evaluation of statin adherence in a sizeable proportion of pharmacy stores that provide service to 2 major cities in Saskatchewan, Canada. Within each store selected, we captured all subjects who were new users of statin therapy. Also, our data appeared reliable in that rates reported from our sample were very similar to those previously reported. ${ }^{15}$

\section{Limitations}

Several limitations must be considered. The most important limitation relates to the way we categorized the community pharmacy stores. We categorized the community pharmacy stores in broad categories that may not have captured the important physical or other characteristics that might be associated with differences in customer service and patient education. Larger differences in adherence might have been detected if community pharmacies were categorized by other criteria. Pedan et al. (2007) found that significant variability in statin adherence can be observed within stores belonging to the same national chains. ${ }^{16}$

Second, administrative databases inherently lack detailed patient-level information. Therefore, it is possible that cohorts differed in important clinical, demographic, or socio-economic factors that could not be identified. Although most of the available baseline characteristics except age appeared similar between the categories, we cannot evaluate the extent to which selection bias influenced our results. In other words, we cannot rule out the possibility that adherent patients are more likely to patronize a certain type of pharmacy.

Third, as with all administrative database studies, we assumed that filling a prescription means the medication was actually taken. Although this assumption would appear to be realistic, ${ }^{19}$ we cannot say with complete certainty that the medication was consumed. To rule out the possibility that compliance packaging-a practice commonly used in Canada, in which prescrip- tions are automatically packaged and renewed weekly-might have influenced our results, we analyzed the frequency of prescriptions in each cohort that contained fewer than 14 dispensed tablets. We found this percentage to be very low; therefore, compliance packaging is unlikely to have influenced our results.

Fourth, we calculated adherence using a tablets per day measure instead of a standard calculation because days supply was not captured by Saskatchewan Health and Extended Benefits Branch during the period of this study. However, statins are almost exclusively prescribed once per day. Fifth, we did not have eligibility data and therefore had to depend on a crude measure-the presence of at least 1 prescription drug claim for any medication - to estimate each individual's ongoing beneficiary status in the database. This proxy could have resulted in removing from the sample patients who were still eligible for benefits. Among patients using a statin as their only medication, the criterion would have resulted in removing nonpersistent statin users from the sample. However, this proxy measure was applied to subjects in all 3 pharmacy categories analyzed so we would not expect it to have influenced the between-group comparisons. Although adherence results at the end of years 2 and 3 might have been affected by the number of patients lost to follow-up, we still had access to over 5,000 subjects with at least 3 years of data. Furthermore, only 410 (3.2\%) of all new statin users were excluded because of an observation period less than 1 year, leaving 8,699 subjects available for the 1-year adherence analysis.

Finally, despite the relatively large sample, our pharmacies were not randomly selected. However, the selection process was carried out by personnel at the Saskatchewan Prescription Drug Plan who were not involved in our study and took great care to ensure the privacy and confidentiality of all information provided. Although $35 \%$ of all pharmacies providing service to the 2 major urban centres in Saskatchewan were captured and analyzed, these results may not be generalizable to all pharmacies or communities, especially those in rural settings.

\section{Conclusion}

During the first year after initiating statin pharmacotherapy, subjects demonstrated low rates of adherence, measured as tablets per day of at least $80 \%$, regardless of the type of pharmacy they patronized (47.8\% in department-mass merchandise stores, $55.0 \%$ in chain-franchise stores, and $54.1 \%$ in independent-banner stores). Although the differences by type of pharmacy reached statistical significance, their clinical importance is not evident. These data reinforce the fact that the problem of nonadherence appears to exist among all types of community pharmacies, regardless of their categorization. Further studies are needed to determine if other methods of categorization (i.e., by clinical service) may help identify characteristics of community pharmacies that influence medication adherence in a positive way. 


\section{Retrospective Observational Assessment of Statin Adherence Among Subjects Patronizing Different Types of Community Pharmacies in Canada}

\section{Authors}

CHARITY D. EVANS, BSP, is a PhD student; DARCY A. LAMB, MSc, is Research Officer; JEFFREY G. TAYLOR, PhD, is Professor; DEREK J. JORGENSON, PharmD, is Assistant Professor; KERRY D. MANSELL, PharmD, is Assistant Professor; and DAVID F. BLACKBURN, PharmD, is Associate Professor, University of Saskatchewan, College of Pharmacy and Nutrition, Saskatoon, Saskatchewan, Canada. DEAN T. EURICH, PhD, is Assistant Professor, University of Alberta, School of Public Health, Edmonton, Alberta, Canada; and WILLIAM M. SEMCHUK, PharmD, is Manager of Clinical Pharmacy Services, Regina Qu'Appelle Health Region Pharmacy, Regina, Saskatchewan, Canada.

AUTHOR CORRESPONDENCE: David F. Blackburn, PharmD, University of Saskatchewan, College of Pharmacy and Nutrition, 110 Science Place, Saskatoon, Saskatchewan S7N 5C9, Canada. Tel.: 306.966.2081; Fax: 306.966.6377; E-mail: d.blackburn@usask.ca.

\section{DISCLOSURES}

This study was funded by a research grant from Saskatchewan Health and Merck-Frosst Schering. Charity Evans receives funding through a Canadian Institute of Health Research Clinical Research Initiative Fellowship, and Dean Eurich receives a salary support award from the Alberta Heritage Foundation for Medical Research (Population Health Investigator).

Evans, Blackburn, Eurich, and Lamb contributed the study concept and design. Mansell, Semchuk, and Jorgenson developed the request for data from Saskatchewan Health, with the assistance of Evans. All authors but Lamb contributed to data interpretation. The manuscript was written primarily by Evans with the assistance of the other authors. Revisions were made primarily by Blackburn and Evans.

Disclaimer: This study is based in part on de-identified data provided by the Saskatchewan Prescription Drug Plan. The interpretation and conclusions contained herein do not necessarily represent those of the government of Saskatchewan or the Saskatchewan Prescription Drug Plan.

\section{REFERENCES}

1. Van Wijk BL, Klungel OH, Heerdink ER, de Boer A. Effectiveness of interventions by community pharmacists to improve patient adherence to chronic medication: a systematic review. Ann Pharmacother. 2005;39(2):319-28.

2. Kalsekar I, Sheehan C, Peak A. Utilization patterns and medication adherence in patients with type 2 diabetes: variations based on type of pharmacy (chain vs independent). Research Soc Adm Pharm. 2007;3(4):378-91.

3. National Community Pharmacists Association. Independent pharmacies take top honors in Consumer Reports nationwide survey. September 10, 2003. Available at: http://www.ncpanet.org/media/releases/2003/independent_pharmacies_take_top_honors_in_09-10-2003.php. Accessed July 2, 2009.

4. White TJ, Chang E, Leslie S, et al. Patient adherence with HMG reductase inhibitor therapy among users of two types of prescription services. J Manag Care Pharm. 2002;8(3):186-91. Available at: http://www.amcp.org/data/jmcp/ Research-186-191.pdf.
5. World Health Organization. Adherence to long-term therapies: evidence for action. 2003. Available at: http://www.who.int/chp/knowledge/publications/adherence_full_report.pdf. Accessed July 4, 2009.

6. Simpson SH, Eurich DT, Majumdar SR, et al. A meta-analysis of the association between adherence to drug therapy and mortality. BMJ. 2006;333(7557):15. Available at: http://www.bmj.com/cgi/reprint/333/7557/ 15 ? maxtoshow $=\&$ HITS $=10$ \&hits $=10 \&$ RESULTFORMAT $=1$ \&author $1=$ Simpso $\mathrm{n} \% 2 \mathrm{C}+\mathrm{S} \&$ author2=Eurich\%2C+D\&andorexacttitle=and\&andorexacttitleabs $=$ and $\&$ andorexactfulltext $=$ and $\&$ searchid $=1 \&$ FIRSTINDEX $=0 \&$ sortspec $=$ date \&fdate=1/1/1981\&resourcetype=HWCIT. Accessed July 2, 2009.

7. Blackburn DF, Dobson RT, Blackburn JL, Wilson TW. Cardiovascular morbidity associated with nonadherence to statin therapy. Pharmacotherapy. 2005;25(8):1035-43.

8. Ray WA. Evaluating medication effects outside of clinical trials: new-user designs. Am J Epidemiol. 2003;158(9):915-20. Available at: http://aje.oxfordjournals.org/cgi/reprint/158/9/915. Accessed July 4, 2009.

9. Jackevicius CA, Mamdani M, Tu JV. Adherence with statin therapy in elderly patients with and without acute coronary syndromes. JAMA. 2002;288(4):462-67. Available at: http://jama.ama-assn.org/cgi/ reprint/288/4/462. Accessed July 4, 2009.

10. Blackburn DF, Dobson RT, Blackburn JL, Wilson TW, Stang MR, Semchuk WM. Adherence to statins, beta-blockers and angiotensin-converting enzyme inhibitors following a first cardiovascular event: a retrospective cohort study. Can J Cardiol. 2005;21(6):485-88.

11. Benner JS, Glynn RJ, Mogun H, Neumann PJ, Weinstein MC, Avorn J. Long-term persistence in use of statin therapy in elderly patients. JAMA. 2002;288(4):455-61. Available at: http://jama.ama-assn.org/cgi/ reprint/288/4/455. Accessed July 4, 2009.

12. Simons LA, Levis G, Simons J. Apparent discontinuation rates in patients prescribed lipid-lowering drugs. Med J Aust. 1996;164(4):208-11

13. The Pharmacy Group. Community pharmacy in Canada: executive summary. Trends \& insights: 2007 survey of pharmacy owners \& managers. February 2008. Available at: http://www.mckesson.ca/documents/Trends_2007.pdf. Accessed July 4, 2009.

14. Insull W. The problem of compliance to cholesterol altering therapy. $J$ Intern Med. 1997;241(4):317-25. Available at: http://www3.interscience.wiley. com/cgi-bin/fulltext/119157813/PDFSTART. Accessed July 2, 2009.

15. Larsen J, Andersen M, Kragstrup J, Gram LF. High persistence of statin use in a Danish population: compliance study 1993-1998. Br J Clin Pharmacol. 2002;53(4):375-78. Available at: http://www3.interscience.wiley. com/cgi-bin/fulltext/118951840/PDFSTART. Accessed July 2, 2009.

16. Pedan A, Varasteh LT, Schneeweiss S. Analysis of factors associated with statin adherence in a hierarchical model considering physician, pharmacy, patient, and prescription characteristics. J Manag Care Pharm. 2007;13(6):487-96. Available at: http://www.amcp.org/data/jmcp/pages\%20 487-96.pdf.

17. Chodick G, Shalev V, Gerber Y, et al. Long-term persistence with statin treatment in a not-for-profit health maintenance organization: a populationbased retrospective cohort study in Israel. Clin Ther. 2008;30(11):2167-79.

18. Vinker S, Shani M, Baevsky T, Elhayany A. Adherence with statins over 8 years in a usual care setting. Am J Manag Care. 2008;14(6):38892. Available at: http://www.ajmc.com/media/pdf/AJMC_08jun_ Vinker388to392.pdf. Accessed July 2, 2009.

19. Grymonpre R, Cheang M, Fraser M, Metge C, Sitar DS. Validity of a prescription claims database to estimate medication adherence in older persons. Med Care. 2006;44(5):471-77. 